\title{
Formas de relación e intimidad analítica ${ }^{\mathrm{i}}$
}

\author{
James L. Fosshage, Ph.D. ii \\ I.A.P.S.P., New York.
}

Se recoge el texto aportado por James L. Fosshage para su Seminario Clínico en Madrid, con variadas ilustraciones clínicas, y se incluye la versión extensa y comentada de una viñeta clínica publicada en 1997 .

Palabras clave: Formas de relación, Intimidad psicoanalítica, Ética, Transferencia, Contratransferencia.

The text provided by James L. Fosshage for Clinical Seminar in Madrid, with varied clinical illustrations, is collected and includes extensive annotated version and a clinical vignette published in 1997.

Key Words: Forms of Relatedness, Psychoanalytic Intimacy, Ethics, Transference, Countertransference

English Title: Forms of Relatedness and Analytic Intimacy

Cita bibliográfica / Reference citation:

Fosshage, J.L. (2016). Formas de relación e intimidad analítica. Clínica e Investigación Relacional, 10 (2): 393-416. [ISSN 1988-2939] [Recuperado de www.ceir.info ] DOI: 10.21110/19882939.2016.100204

\footnotetext{
i Texto aportado por James L. Fosshage para el Seminario Clínico realizado en Ágora Relacional (Madrid) el 7 de Mayo de 2016, que está basadso en un original de 1994 varias veces revisado por el autor. Traducción castellana (Versión de trabajo) de Andrea Iturriaga Medrano. Se incluye como apéndice la traducción de la viñeta clínica (Amanda) publicada en 1997 con los comentarios que el Prof. Fosshage realiza en su exposición en el Seminario Clínico de 2016 en Madrid, haciendo referencia a su exposición sobre la transferencia del día anterior, que han sido compilados y traducidos por Montserrat Gómez.

\begin{abstract}
ii James L. Fosshage, PhD, es ExPresidente de la International Association of Psychoanalytic Self Psychology y el anterior presidente Association for Autonomous Psychoanalytic Institutes (AAPI). Es el co-fundador y director del consejo del National Institute for the Psychotherapies (NYC), miembro facultativo fundador del Institute for the Psychoanalytic Study of Subjectivity (NYC), y profesor de Psicología Clínica en el Programa Postdoctoral de Psicoterapia y Psicoanálisis de la Universidad de Nueva York. Entre sus libros están: Dream interpretation: A comparative study, edición revisada, en el que es co-autor junto con Clemens Loew, Self and Motivational Systems: Toward a theory of Psychoanalitic Technique, The Clinical Exchange: Technique from the Standpoint of Self and Motivational Systems, and Spirit of Inquiry: Communication in Psychoanalysis, todos ellos con la colaboración como co-autores de Joseph Lichtenberg y Frank Lachmann. Actualmente tiene su propia consulta privada como psicoanalista y psicoterapeuta en New York City y en Tenafly, New Jersey.
\end{abstract}


He querido escoger una paciente y un proceso analítico, el cual discurrió durante cuatro años, para ilustrar las diferentes formas de relación y las consiguientes formas de intimidad. Anteriormente he sugerido (1997a) que las necesidades de apego y las formas de relación son conceptualizadas significativamente en un continuo. Por un lado, las necesidades del self y la relación self-objeto del self destacan en la experiencia. Esto se refiere al mismo ámbito que las necesidades y relaciones especulares y de idealización del objeto del self que enuncia Kohut $(1971,1984)$ - lo que Stern (1985) denomina como otro un regulador del sí mismo y que Shanes y Gales (1997) acuñan como el otro que transforma al self. Entonces aparecen necesidades de y relaciones que incluyen al self con el otro que Stern (1985) y Benjamin $(1988,1995)$ llaman relación intersubjetiva - lo que Shanes y Gales refieren como el self con el otro que comparte interpersonalmente y, más recientemente, lo que Jacobs (1998) ha denominado tan convenientemente como relación entre sujeto y sujeto ${ }^{1}$. Finalmente están lo que yo llamo necesidades de centrarse en o preocuparse del otro, relación de "cuidado" por ejemplo, un padre cuidando a su hijo, un profesor a su alumno o un analista a su paciente.

Todas las formas de relación pueden dar lugar a experiencias vitalizadoras o experiencias del objeto del self para cada uno de sus participantes. La mayor parte del trabajo analítico pondrá de manifiesto los cambios de prioridades en cuanto a necesidades y formas de relacionarse que tienen que ser examinadas desde la perspectiva de cada uno de los miembros de la díada analítica. Por ejemplo, cuando las necesidades del self están colocadas en un primer plano para el paciente, esto requiere la recíproca preocupación por el otro o una relación "de cuidado hacia el otro" por parte del analista. La aparición inmediata o revelación de la subjetividad del analista dentro de la interacción está más delimitada. Al contrario, la necesidad de relacionarse intersubjetivamente que tiene el paciente requiere de una relación intersubjetiva recíproca por parte del analista. El continuo reconocimiento mutuo (Benjamin, 1988, 1995; Aron, 1996) necesita una mayor revelación de la subjetividad del analista. Y, por último, cuando el paciente centra su atención en el analista o le demuestra preocupación, el analista debe sentirse cómodo con el hecho de que sus necesidades de objeto del self pasen a un primer plano y reciba dicha atención y cuidado del paciente. Cada forma de relacionarse del paciente, junto con la contraparte del analista contribuye al carácter particular de intimidad de cada uno de los componentes de la díada.

Hace siete años recibí una llamada de teléfono durante el fin de semana de un colega analista. Yo no le conocía apenas. Él, le llamaré Jay, era un hombre de unos sesenta años. En las pocas veces que habíamos coincidido me parecía alguien muy brillante, locuaz y discutidor. Jay me contó que se había enamorado de una de sus pacientes. Tras consultarlo con su anterior analista, él decidió expresarle sus sentimientos y deseos de tener una relación amorosa con ella y, poco después, el tratamiento acabó. Tras su invitación, ella se fue a vivir 
con él a los cuatro días de finalizar el tratamiento. Ellos estaban de acuerdo entonces en que ella necesitaba un analista y tres semanas después yo recibí la llamada. En su petición de que yo la viera a ella, tomándose cierta confianza, reconoció que se trataba de una situación muy poco usual y bastante problemática. Le dije que la vería y le propuse que ella me llamara a mí. Me dijo entonces que ella estaba junto a él, y se puso al teléfono. Con voz clara, expresó con entusiasmo, aunque de forma directa, su deseo de verme, por lo tanto, fijamos una cita.

Varios días después vi a Samantha por primera vez. Samantha, una mujer de 37 años, según mis ojos y mis oídos tenía una forma de hablar correcta, era bastante atractiva, vestía con un estilo casual y moderno, tenía cierto encanto y hablaba con franqueza. Su franqueza llevaba una tensión que yo sentí que era parte de su batalla por silenciar sus influencias. Su estado de ánimo era bueno. Ella "volaba alto" y claramente era esclava del amor idealizado de su nuevo novio/anterior analista. Percibí que su buen estado de ánimo no sólo estaba relacionado con los primeros estadios del "estar enamorado" que incluye una mutua idealización fortalecedora del self, sino que también mostraba de algún modo el esfuerzo valiente, y también tenso, de dominar críticas anticipadas e incluso sentimientos negativos de sí misma. Ella me gustó, sentí interés y me sentí comprometido, me pregunté dónde nos llevaría nuestro trabajo.

Su primer tratamiento, comentó ella, había tenido lugar varios años atrás cuando tenía problemas dentro de su matrimonio y, poco después, se había divorciado. Se había casado a los veinte años de edad y divorciado tres años más tarde. Su terapeuta había sido un "analista Freudiano" que conocía su familia. Ella críticamente le describió como alguien cerebral, sin empatía, distante y nada afectuoso - señales de aviso, pensé, muy posiblemente reflejando trauma previo y aquello que yo no debía ser. Sintiendo que él era alguien demasiado cercano a su familia, ella acabó "manipulando al terapeuta y orquestando la sesión para entretenerle y así evitar ciertos temas". Terminaron después de dos años, y exclamó ella "acabó acostándose conmigo" y ella se sintió culpada por él y acabó sintiéndose peor.

Aproximadamente diez años después buscó tratamiento con Jay. En ese momento ella se sentía profundamente deprimida y tenía pensamientos suicidas. Dijo que sentía un gran conflicto "entre aquello para lo que había sido educada y su self nuclear interior... mi self interior había sido aplastado y pedía ser liberado o yo moriría... yo era una niña perfecta olvídalo - no soy la reprimida y elegante chica suizo-alemana". Le habían enseñado a "controlar intelectualmente" sus sentimientos. Como resultado, ella sentía "que salía de ella una mujer amazona que había sido hasta entonces contenida y olvidada" Comenzó su análisis con Jay acudiendo cuatro o cinco veces en semana a sesión y tomando Prozac. El análisis duró seis meses. 
Según relató, Samantha rápidamente se había sentido muy involucrada en su trabajo con Jay, ayudada por el sentimiento de sentirse profundamente entendida por primera vez en su vida. Al establecerse una relación idealizada y especular con el objeto del self, su ánimo mejoró considerablemente y se suspendió la medicación. El análisis iba bien hasta que las necesidades del analista entraron directamente a escena. Ella me describió como ellos estrechaban sus lazos cada vez más y comenzaron a expresarse un afecto mutuo. Ella relataba abrazos al final de las sesiones, iniciados por Jay².

Ocasionalmente tras sus sesiones a última hora, él la llevaba en coche a casa, aunque era algo confuso para ella, en cambio, lo sentía como parte de la creciente cercanía entre ambos. Entonces Jay, que llevaba un tiempo divorciado, le dijo que estaba enamorado de ella y que quería terminar con el tratamiento y casarse con ella. Ella respondió positivamente, era la primera vez que se sentía tal comprensión y conexión con un hombre. Terminaron entonces el tratamiento $y$, poco después, se comprometieron.

Samantha y yo conectamos con facilidad durante la primera sesión. Pronto fui consciente de la violación ética por parte de Jay y de las directrices para denunciarlo; en cambio, estaba más preocupado del bienestar de Samantha. Denunciar a Jay, sabía que conllevaría la terminación del tratamiento con Samantha. Además, esto afectaría a su relación y obstaculizaría que Samantha encontrara su propia manera de pensar la situación. También pensé que el analista de Jay sabía todo y era responsable junto con él. Decidí no transmitirle a Samantha mi preocupación acerca de lo que había ocurrido, Samantha estaba "enamorada" y cualquier muestra de preocupación, pensé, provocaría una aversión comprensible que aparecería para proteger la conexión amorosa con Jay. Tuve que vencer mis impulsos de juzgar la situación recordándome que en verdad yo no sabía si la relación podría funcionar, y que incluso alguna vez ese tipo de relaciones funcionaban. Creo que mi apertura a esta posibilidad facilitó que escuchara con detenimiento el relato de Samantha y sus propias valoraciones. Ante lo que ella misma había dicho acerca de lo que parecía ser un conflicto fundamental entre su self nuclear y cómo había sido educada, me di cuenta entonces de que no quería imponerle otro criterio y otra agenda ${ }^{3}$. Decidimos vernos dos veces en semana debido a que, además de temas económicos, creo que ambos sabíamos que ella no quería precipitarse todavía hacia otra intensa relación analítica. Durante la siguiente sesión Samantha habló de que su hermano mayor había muerto en un accidente de coche hace veinte años. En ese momento ella pasó a ser la única hija. En cambio, en un primer momento ella se centró en su relación con Jay y la preocupación de sus padres acerca de esta relación. Samantha describió a sus padres como "cerebrales, controladores, intelectuales y asustadizos". Su padre había dicho en tono crítico - "Una paciente que se casa con su terapeuta, iel sueño de toda mujer!". Él la veía como una hija nula que necesitaba ser cuidada 
por un hombre cuidador. Su madre también era crítica y le dio a Jay lo que Samantha describió como una "dosis de manipulación" la primera vez que se conocieron, diciéndole "Debes haber elegido entre todas tus pacientes". Desgraciadamente Samantha estaba muy acostumbrada a estos comentarios degradantes frente a "malos comportamientos". Debido al escepticismo de sus padres, se había hecho incluso más necesario que ella permaneciera firme en su compromiso y amor hacia Jay.

Durante el curso de las siguientes seis semanas, Samantha empezó a contarme acerca de su sensaciones y experiencias internas, muy a menudo utilizando sus sueños que revelaban un conflicto intenso y dramático. Todo esto no podía manifestarse sin poner en peligro seriamente sus relaciones con el resto, así como a su estado de ánimo frágil que se pone de manifiesto en sus sueños. El primer sueño que contó tras cuatro semanas de tratamiento fue el siguiente:

Soy una mujer oriental, su piel es blanca, su pelo oscuro, está desnuda. El cielo está pálido - en calma. Hay una enorme duna de fina arena blanca. Estaba en la cresta de la duna para ver el océano - un lugar en el que siento paz. Al pie de la duna había dos niños orientales - pequeños, estaban muertos. Estaban tumbados sobre sus estómagos flotando en el océano. Habían muerto por ser golpeados en la espalda con un enorme ramo de pequeñas rosas de color rosa. A mí también me habían golpeado en la espalda.

Una y otra vez yo subía a la cresta de la duna para poder ver. Los niños cambiaban. Unas veces éramos yo y mi hermano - otras veces mis padres. Les estoy haciendo daño en mi deseo de crecer. [Comentó ella fuera del sueño] No pretendía hacerles daño. Otras veces eran los niños que nunca he tenido. Me desperté con mi cuerpo totalmente en tensión. Como si hubiera buitres que fueran a picotear mis huesos.

En nuestra conversación siguiente, Samantha mencionó cómo, en algún momento del pasado otoño, había tenido grandes sentimientos suicidas y le había aparecido una roncha en su espalda y tuvo un sueño en el que su madre le había apuñalado con un cuchillo la espalda. Aquí, en este sueño eran las rosas rosas las que asestaban los golpes letales. "Las flores se dieron en nombre del amor", explicó, "pero a mí me mataban continuamente, me maltrataban, me controlaban. Ellas hicieron algo precioso pero letal." Ella habló de las dos partes de sí misma, "Aquello para lo que me han educado y quién soy en el interior... no puedo unir a las dos". Para ella, crecer, vivir desde el interior hacia el exterior en lugar de fuera hacia dentro, conllevaba el hacer daño a sus padres, incluso matarlos. Acabó temiendo a los buitres. Retrospectivamente, estos aspectos fundamentales plantearon mucho de lo que aún estaba por llegar.

Progresivamente su historia de vida se fue desplegando, pero de una manera inusualmente fragmentada. La elaboración de sus sueños traía, muy a menudo, piezas que 
podrían ser incorporadas (a su historia). Aunque era tremendamente elocuente, su narrativa acerca de sí misma estando despierta aún no era coherente del todo, estaba repleta de fragmentos disociados. Pude percibir ese intenso conflicto entre sus propias experiencias perceptivas, afectivas y cognitivas - estas le servían de anclaje a su sentido del self $-\mathrm{y}$ las expectativas y deseos de sus padres que imposibilitaban la formación de un sentido de su self más cohesionado. Consumida por este conflicto, y sus padres por los suyos, su experiencia relacional no había generado el espacio necesario y la tranquilidad interna para poder reflexionar, dar forma y articular una imagen más coherente de su vida. Asimismo, incluso el breve resumen que recogen los próximos párrafos fue construido durante un periodo de tiempo considerable.

Su padre tenía mucho éxito dentro del mundo de las artes y su madre había recibido una buena educación y había trabajado en publicidad. De origen suizo alemán, ellos criaron a sus hijos con unos fuertes valores respecto a la educación, la música, la cultura, el trabajo duro, la implicación y la dedicación. Reglas y normas estaban a la orden del día. Muy a menudo, su madre le hablaba histéricamente a Samantha, sin dejarle hablar a ella. El mal carácter y los estallidos de ira de su madre aparecieron más tarde en el tratamiento. Según ella describió, su madre y su padre eran personas ocupadas y siempre en tensión, las cosas tenían que hacerse "bien". Mientras que la tensión emocional estaba siempre en el ambiente, había muy poco espacio para la reflexión acerca de experiencias relacionales emocionales. Ella y su hermano, cuatro años mayor, peleaban mucho. Incapaz de poner de manifiesto la tensión emocional que había y así lograr averiguar su significado, su padre acabó cerrando con clavos la puerta que unía sus habitaciones.

Samantha había experimentado a su familia como muy enfadada y en tensión, en cambio, se enorgullecía de ellos. Había sido educada para ser un ejemplo de hija perfecta, y una joven elegante. Al tener éxito en estos roles se alimentó así su confianza en su inteligencia, en su atractivo y en su estilo, en cambio pareció darse cuenta de que debido a la imposición de las agendas de sus padres, ella se había visto forzada a subordinar gran parte de sus propias experiencias perceptivas y afectivas. Ella continuaba librando una terrible guerra entre "aquello para lo que me han educado y lo que soy en mi interior".

Una gran tragedia sacudió a la familia cuando su hermano, con veinticinco años, murió en un accidente de coche. Sus padres se enfrentaron a lo ocurrido cerrándose emocionalmente. No hablaban de su hermano. Era como si él nunca hubiese existido. Poco después vendieron su querida casa de la playa, ese lugar en el que estando junto a la naturaleza y con más tiempo disponible, habían vivido más plenamente como una familia. La pérdida de su hermano, la consiguiente pérdida de conexión emocional con sus padres y la 
pérdida de su preciada casa en la playa causaron grandes daños emocionales a Samantha. Sus sueños eran largas narrativas complejas que muy a menudo eran esfuerzos desesperados por lidiar con estas pérdidas. La siguiente pequeña parte de su segundo sueño cuenta con claridad la historia:

Tengo la edad que tenía entonces, también ahora. Vamos a vender la casa. Una pareja viene a verla. Para mí es muy importante que ellos sean una pareja que entienda realmente la casa. No creo que haya una pareja así. D, T (mis padres) y yo hemos pasado todo este tiempo dejando bien la casa para venderla. Nuestros corazones están llenos de dolor. No queremos vender la casa, cada uno de nosotros por nuestras propias razones, pero no podemos hablar entre nosotros acerca de estas razones. Cada uno estamos encerrados en nuestro propio dolor y tristeza, y debido a este dolor juzgamos a los demás y a nosotros mismos. Asumimos una posición y entendemos que el resto de la familia hará lo mismo. Procedemos a cumplir con la "manera" correcta de lo que aparentemente tenemos que hacer: deshacernos de la casa que a T (mi madre) le recuerda a mi hermano. Ella tiene la iniciativa y nosotros la seguimos ya que ella está muy triste y nos explica que la casa es demasiado grande para mantenerla y que debemos venderla.

Al mismo tiempo, durante los primeros dos meses de tratamiento la relación entre Samantha y Jay se fue deteriorando. A diferencia de su minuciosidad en la forma de escucharla y entenderla en la relación analítica, ella comenzó a sentirle como alguien controlador y demandante sin atender apenas a sus propios deseos. Por ejemplo, ella se percibía a sí misma como una persona muy sexual, en cambio, ella encontró que él era sexualmente controlador e irrespetuoso. Él reaccionaba con enfado a sus objeciones y reclamos, algo que le hacía evocar a su familia. Tuvo un sueño en el que se casaba con Frankenstein - se trataba de Jay. Trataba de escapar. En su sueño, tanto él como ella presentaban malformaciones. Esto no sólo hacía referencia a cómo estaba experimentando últimamente a Jay, también ella había pensado durante años que algo malo le ocurría. En el consiguiente proceso de una rápida e imparable desidealización, comenzó a ver a Jay como un hombre mayor y solo, terriblemente controlador y centrado en sí mismo. Además, tenía una actitud defensiva y era incapaz de reflexionar o hablar sobre ello. A su vez, Samantha se sintió horrorizada y avergonzada de haber accedido a dicha situación. Recordando aspectos acerca de su anterior análisis, pensó que cuando había comenzado a hablar de sus sentimientos sexuales, Jay le había animado a explicarlos de un modo detallado. Ella se dio cuenta de que en algunos momentos él se había excitado sexualmente. Más tarde, en algunas ocasiones él llegó a responderle con insinuaciones sexuales. Ella había reaccionado positivamente, algo que ahora le horrorizaba. Los ingredientes de dichas respuestas sentimiento de afirmación, excitación sexual, intimidad, sentirse entendido y rendirse al otro 
- no se pudieron analizar en ese momento. En cambio, su desconfianza, su sentimiento de traición, el enfado y la culpa se intensificaron. A los dos meses ella había roto la relación en contra de las furiosas protestas de Jay, y volvió a su apartamento.

Sus sentimientos de abuso y traición por parte de Jay resonaron en profundidad con sus experiencias del pasado. De un modo gradual aparecieron recuerdos acerca de que su hermano le había hecho algunas proposiciones sexuales y, durante su adolescencia, un vecino de confianza había intentado seducirla insistentemente. El maltrato físico había ocurrido cuando su madre enfurecida le atacaba, abofeteándola y "dándole una enorme paliza". También la relación que tenía con sus padres la experimentaba con una profunda sensación de traición en sus críticas y en la imposición de las propias agendas de los padres.

Durante los siguientes cuatro meses, se fue sintiendo cada vez más enfadada por la traición de Jay y su manipulación de una relación analítica de confianza. Sintió que había sido víctima de abusos, aunque también sintió una profunda vergüenza por su implicación. Finalmente decidió demandarle, algo que para ella suponía un intento de reafirmarse a sí misma, dañarle a él y superar su sensación de victimización. Su abogado me pidió que yo participara. Teniendo en consideración las repercusiones posibles de esto para Samantha (entre las cuales una de las más importantes era el potencial que tenía la demanda de predominar en el análisis), enfaticé la importancia de proteger nuestra relación analítica. También pensé que en el juicio al analista se le podría desprestigiar fácilmente como interesado y sesgado, por lo que quedaría ya poco que ganar con mi participación directa. Mientras que yo tenía claro lo importante que era para Samantha mi apoyo en el pleito, con su consentimiento y su posterior agradecimiento, rechacé participar en dicho pleito. Siguiendo la petición de su abogado, remití a Samantha a un psiquiatra que le aportaría la evaluación psiquiátrica necesaria para el caso. Tras negociaciones entre los abogados, Jay la amenazó a ella y a su abogado con violencia. Poco después, ella aceptó con satisfacción y pena un acuerdo sin pasar por juicio ocho meses después de la separación.

Lo ocurrido con Jay había sido traumático y las repercusiones significativas. ¿Podría volver a confiar en un analista? ¿Podría volver a confiar en un hombre? Juró que nunca más volvería a tener sentimientos de carácter sexual por su analista, algo que claramente se dirigía a mí, ya que consideraba que yo también sería incapaz de contenerlos y me excitaría y la traicionaría. Se sentía amenazada por el poder del analista así como también por su propia capacidad de seducción. Ella escribió lo siguiente,

No puedo aceptar que permitiera que esto me ocurriese. No puedo entender que yo fuese víctima. No puedo aceptar el hecho de que yo haya participado en esa relación ... me siento violada, avergonzada, trastocada, inútil, repugnante, furiosa, despojada, traicionada, abandonada, jodida, abusada sexualmente, maltratada, asqueada. Me 
siento atrapada dentro del rastro de abuso y traición en el que me ha dejado. Me siento sucia, incompleta, totalmente en peligro. No puedo aceptar que fuera tan inútil e incapaz de actuar de otro modo.

Cuando la desconfianza sobresalía dentro de la relación analítica, yo trataba de quedarme en las atribuciones de la transferencia (Lichtenberg, Lachmann, y Fosshage, 1996). Con esto quiero decir que trataba de experimentarlas y entenderlas teniendo en cuenta cualquier aspecto que pudiera ser un detonante entre nosotros, tanto por mis contribuciones como/o por sus anticipaciones o construcciones basadas en su anterior relación analítica y la relación con sus padres. A pesar de su desconfianza, Samantha parecía experimentarme como alguien protector y afectuoso - base de una transferencia idealizadora del objeto del Self - lo cual correspondía a cómo yo me sentía hacia ella. Cada vez más fue experimentándome como "firme", esto le ayudó a asegurar que nuestra relación no se descontrolaría, un prerrequisito fundamental para nuestra co-creación de una nueva experiencia relacional. Durante esta fase del análisis, la relación con el objeto del self era lo que para ella estaba en primer plano; y para mí, mi actitud de "cuidado" o preocuparme por ella establecieron una relación recíproca. Esto dio lugar a una particular cercanía, similar a la de un padre con una hija joven, algo que para ambos resultaba satisfactorio. En cambio, experimentarme completamente como a una persona con sus necesidades adicionales, era en ese momento del análisis un poderoso detonante de terror a poderse exponer a traición, dominación y abuso. Así pues, su experiencia de mi subjetividad durante ese tiempo, lo aprendimos ambos, necesitaba estar delimitada a mis esfuerzos "de cuidado" para poder co-crear la seguridad y protección que necesitaba.

En el ámbito laboral Samantha había abandonado recientemente un puesto de trabajo a tiempo completo en una empresa de arte, debido a que tanto la estructura corporativa como su propio jefe eran demasiado intrusivos y controladores. Trabajaba como freelancer pero tenía problemas económicos y sufría por la falta de orientación profesional. Quería escribir, pero le faltaba confianza y no había sido capaz de mantener un esfuerzo constante.

El proceso analítico siguió avanzando y ella comenzó a enfrentarse a recuerdos y a la vida afectiva que había permanecido congelada. Sus sueños, los cuales dejaban claro su talento creativo, eran angustiosamente largos y dolorosos. Al tiempo que empezaba a escribir sobre ellos, comenzaron a emerger recuerdos muy dolorosos. He seleccionado pequeñas partes de un sueño que tuvo aproximadamente a los diez meses de entrar en tratamiento. El sueño comienza con Samantha en la playa viendo surfear a varios surfistas durante la tarde. Ella tiene que ir a recoger a su padre y empieza a preocuparse de que llegará tarde y su padre le acusará de irresponsable. Ella escribe lo siguiente: 
Vuelvo de nuevo al lugar donde estaba. Pero estoy enfadada y siento que me estoy "desmadrando". Los surferos se han ido, en cambio han dejado sus tablas más atrás, en posición vertical junto al muelle. Puedo ver los anzuelos en la arena y las cañas de pescar junto a ellos. Los anzuelos sobresalen de la arena. Primero me siento y los miro, y después ando hacia ellos con decisión, todo lo que hay que hacer y no hay que hacer, las restricciones, las reglas, los controles, los deberías, los tienes que hacer, los siempre, los nunca y los hazlo ahora mismo, todo esto que mis padres me han impuesto suena en mis oídos al mismo tiempo que ando a través de la playa. Quiero tocar esa tabla de surf azul oscura, está posada, la aleta está frente a mí, la parte trasera está ligeramente desgastada, el color se ha quitado al arrastrarla por la arena de la playa después de estar en el agua. Es como una ballena azul con aletas. Ando por encima de los anzuelos y puedo sentir y oír como éstos van pinchando mi piel, curvándose y saliendo por el lado contrario. No me importa. Debo alcanzar y tocar esa tabla azul. Siento el dolor por los anzuelos, pero me siento descorporeizada de éste al mismo tiempo.

En su impertérrito intento por tocar la tabla azul, en un primer momento ella entiende necesario "descorporeizarse" del dolor de los anzuelos clavándose. Más tarde en el sueño, ella empieza a sentir un insoportable dolor al tratar de liberarse de los anzuelos. Ella sabe que sus padres le regañaran. Esa misma noche hay un concierto y se da cuenta de que les ha estropeado la tarde ya que ellos tendrán que llevarla al hospital para que le extraigan los anzuelos. La idea que sobresalió significativamente durante nuestra discusión del sueño fue que su necesidad de tocar la tabla azul y sentir su belleza, a pesar de los visibles anzuelos, y su necesidad de desafiar las constantes advertencias y prohibiciones de sus padres le ponían en peligro. Sus padres no iban a ser comprensivos, sino que se iban a estar furiosos con ella, alimentando aún más su desesperado esfuerzo por encontrar, a pesar del peligro y con una actitud de desafío ante las imposiciones de sus padres, algo de belleza, de libertada, algo de paz como la que encontró en la tabla de surf azul oscura. ${ }^{4}$

Al escribir este sueño, recuerdos traumáticos irrumpieron en su consciencia - Recordó ser atropellada por un coche y su madre furiosa le había golpeado; ser llamada a cenar, obligándola a abandonar a su gato para que muriera solo; su brazo roto del que sus padres no se ocuparon inmediatamente; cuando no le contaron la verdad tras una cirugía dental; no le transmitieron la muerte de su hermano hasta ocho horas después; y su padre gritándola cuando ella, con once años, le había visto desnudo, "la vergüenza que él me hizo sentir".

Similares variantes de este sueño, que tuvieron lugar entre los 8 a 10 meses previos, tenían que ver con ella revisando su habitación antes de que ella y sus padres abandonaran la casa de la playa después de haberla vendido. Se daba cuenta de que los cajones y armarios estaban Ilenos. Ella escribió, 
Todo lo que tengo, recuerdos simbolizados en mis pertenencias, caían, caían a presión sobre mis manos. Soy siempre la última. Los demás van juntos. Parece que, o han negado que sea difícil para ellos marcharse. Esta vez, ellos ya están en la fila del ferry, y yo estoy desbordada sentada en mi habitación encontrando más y más cosas que llevarme. Ya me han castigado antes por tener demasiados bolsos. El resto de la casa parece un museo - he escrito mausoleo. Solamente mi habitación está desordenada o viva...

Entendimos que, por un lado, estaba colmada de recuerdos que necesitaban ser revisados $y$, por otro lado, ella intentaba desesperadamente capturar y conservar los recuerdos que le podrían proporcionar una continuidad de sí misma. Pero ella siempre sentía pánico ante el rechazo, la impaciencia y la ira de sus padres.

Ella no tuvo tiempo de revisar una a una sus pertenencias, de valorar, reflexionar, entretenerse y llevarse consigo o deshacerse de las que hubiera querido.

A medida que Samantha iba siendo capaz de disociar menos, su mundo interior de intenso conflicto y recuerdos dolorosos aparecieron al completo, siendo en algunos momentos extremadamente aterradores. Ella experimentaba fuertes deseos de tirarse de alguna de las ventanas de su apartamento en la décima planta que llegamos a entender como saltos hacia la "libertad", libre de expectativas, de restricciones y de confusión interna. Ella tenía mucho miedo, y yo empecé a estar profundamente preocupado, de que en un punto álgido de dolor ella pudiera decidirse por este último intento desesperado y acabar con el sufrimiento tan intenso. Tenía prescrita medicación, en cambio su miedo al abuso y a ser dominada permanecían. Yo la veía cuatro veces a la semana y le comenté la posibilidad de vernos una quinta, tratando así de crear un lugar segura para que pudiera expresar, contener y entender sus miedos. Mientras que normalmente ella acudía a mí para obtener seguridad, apoyo y comprensión, cuando sus miedos paranoides se volvieron más intensos, comenzó a tener miedo de que yo, también, le torturaría e intentaría controlarla para mi propio beneficio. Un momento muy conmovedor ocurrió cuando ella estaba acurrucada y sollozando en la silla, sintiéndose totalmente indefensa y desesperanzada al enfrentarse a estos miedos, yo entonces incliné mi mecedora ligeramente hacia delante. Ella, sobresaltada, puso las manos arriba contra la pared como si quisiera trepar para protegerse. Tuve la profunda sensación de una niña pequeña siendo pegada y no teniendo lugar al que dirigirse más que la pared. Con calma y de una manera tranquilizadora, describí con delicadeza lo que acababa de ocurrir y cómo ella se había sentido tan insegura y aterrada. Una vez que ella se hubo calmado, hablamos juntos del poder de sus miedos y del origen de éstos.

Durante ese periodo en particular, su miedo al suicidio, algo que experimentaba como un impulso a saltar hacia la libertad, se intensificó. Debido a que ella vivía sola, ambos 
estuvimos de acuerdo en que para el alivio de ambos, ella necesitaba un hospital para crear un lugar suficientemente seguro en el que ella, integrando los recuerdos y afectos disociados hasta el momento, podría experimentar más intensamente los miedos que aparecían. Como parte de su proceso de reintegración ella necesitaba un lugar donde, a diferencia del contexto de un despacho, ella pudiera gritar tan intensamente como necesitara sus miedos e ira. Afortunadamente, en ese momento pude encontrar un hospital privado que disponía de una planta en la que sus trabajadores tenían un enfoque psicoanalítico. Estuvo allí durante un mes, trabajando con un psicólogo del hospital que, casualmente, le recordaba a mí. El hospital le facilitó su necesidad de seguridad para poder experimentar todos los recuerdos y emociones aterrorizadoras. Ella gritaba sus miedos y su ira. Se agachaba en una esquina, sollozaba y hablaba. Tenía un equipo para tratamiento grupal e individual, me tenía a mí para sesiones por teléfono, y el compañerismo y apoyo de otros pacientes que sentían parecido a ella, todos ellos co-crearon un lugar suficientemente seguro, un entorno sostenedor (Winnicott, 1965; Slochower, 1996) para sentir, expresar y contener sus miedos y su ira.

Rememorando y reconociendo lo que había ocurrido en su familia durante este periodo, Samantha sentía mucho miedo de sus padres y rechazó verles. Cuando, hacía el final de su estancia, ella estuvo preparada para verlos, les invitó a que fueran. Su madre, en cambio, se resistió ostensiblemente debido a otros compromisos y finalmente el encuentro no tuvo lugar. Comprensiblemente Samantha estuvo muy enfadada, y esta vez, lo expresó con firmeza.

Cuando le dieron el alta, Samantha estaba débil pero estable. Los miedos habían disminuido y nosotros continuamos con nuestro trabajo analítico. Pasado un año, Samantha sintiendo cierta preocupación pero con un sentimiento de triunfo, suspendió la medicación. Durante los siguientes años, los miedos disminuyeron y nuestro trabajo adquirió más firmeza. En uno de sus sueños ella estaba en una clase de matemáticas. Al darse cuenta de que necesitaba ayuda, se dio la vuelta hacia el profesor, amable y nada censurador, quien le recordaba a mí.

El me habla tranquilamente, con calma, y mi pánico desaparece, sigo sin entender él proceso que explica para encontrar el resultado, pero al menos me siento menos frustrada y sola. Hace un problema entero por mí, de principio a fin en una hoja, anota todos los pequeños pasos que hace sobre la marcha, sin olvidar nada. Yo miro cómo él escribe - es reconfortante. Arranca la hoja de su cuaderno. Cuando ha terminado, me la da a mí. Ahora siento que tengo un modo de seguir, un marco de referencia para el siguiente problema que se me proponga. Me voy sintiéndome aliviada, menos asustada, menos frustrada. 
En el sueño de Samantha aparece en un primer plano su necesidad de una relación de protección con un objeto del Self idealizado, unido a mi manera recíproca de relacionarme como cuidador para crear seguridad y un reconfortante "marco de referencia" para resolver problemas - una cercanía e intimidad particular.

Sin trabajar constantemente y viviendo sola, poco a poco Samantha empezó a sentirse aislada y necesitada más contacto con personas. Apreciaba especialmente a los grupos del hospital donde ella había podido ser ella misma - algo inusual a lo que ella había experimentado siempre. Le sugerí que se uniera a uno de mis grupos de análisis y así lo hizo. La terapia grupal pasó a ser un lugar donde ella podía practicar ser ella misma y expresarse. Cuestiones acerca de sus sentimientos de desconfianza, sentirse juzgada, controlada y forzada entraron en escena antes o después. Además, ella empezó a ser plenamente consciente de cómo ella, ahora identificando las actitudes de sus padres, podría convertirse en la crítica y controladora "buena chica suizo-alemana", presionando a que otros cambiaran e imponiendo sus planes. En numerosas ocasiones, el grupo fue la familia problemática y amenazante y ella quería abandonar. Estas cuestiones eran trabajadas un y otra vez. Con una desarrollada diferenciación de sí misma y libertad, cada vez más era capaz de responder perceptiva y empáticamente a los otros. El grupo supuso una oportunidad para experimentar las tres formas de relación e intimidad.

Su relación con sus padres cambió drásticamente. Una sesión conjunta con su madre facilitó la comunicación entre ambas. Ella hablaba de una manera más directa y asertiva con sus padres. Se desvinculó con habilidad de los intentos de sus padres de utilizarla en sus conflictos de poder. En una ocasión, su madre intentó darle a ella uno de los objetos artísticos del padre. Al observar un gesto de enfado en su padre, Samantha rebatió que su madre no le había preguntado a él y volviéndose hacia su padre le preguntó cómo se sentía. Al tiempo que ella era capaz de defenderse a sí misma de ellos y no sentirse abrumada, ella era más capaz de aceptar las limitaciones de sus padres y recibir aquello que ellos tenían para ofrecer. A su vez, sus padres, considero, han pasado a ser a menudo cariñosos y comprensivos ${ }^{5}$.

Samantha volvió a quedar otra vez con hombres. Parecía tener alguna dificultad para conocer hombres y en involucrarse románticamente. Samantha fue más consciente de su tendencia a precipitarse a mantener relaciones sexuales con hombres antes de fomentar otros contactos fundamentales. Paulatinamente, a medida que estaba menos preocupada por ser controlada e intimidada, y por consiguiente, más dispuesta a arriesgarse y exponerse emocionalmente, profundizó en sus relaciones con los hombres.

Después de tres años de análisis, Samantha había mejorado considerablemente. Se sentía mucho mejor y muy viva. Sus experiencias afectivas estaban más disponibles para ella 
y eran más soportables. Su confianza en mí había crecido enormemente y expresaba más sentimientos de amor hacia mí. Al final de una sesión, se acercó a mí y abrazándome me dijo que se sentía mía y quería darme las gracias por continuar ahí con ella. Quedó claro que ella estaba tomando la iniciativa, recibí con afecto su abrazo y también le abracé a ella - algo que me resulta cómodo cuando se trata de algo tan apropiado como aquello fue en ese momento ${ }^{6}$. Para los dos, este fue un abrazo muy conmovedor que con enorme poder nos transmitió confianza, afecto y gratitud. A mí me afecto especialmente debido a que, tal y como hablamos en las siguientes sesiones, era la expresión de su profunda confianza y ninguno de los dos la hubiera malinterpretado. Fue un punto de inflexión después de lo que había ocurrido en su análisis anterior. Posteriormente, Samantha en nuestras despedidas extendería su mano para estrechar la mía, o si deseaba me daría un pequeño abrazo, o preferiría, especialmente cuanto estaba enfadada conmigo, no tener contacto en absoluto. Nuestra rutina consiste en que ella siempre tiene la iniciativa, expresando también verbalmente sus sentimientos. Estoy convencido de que esto ha profundizado su experiencia afectiva, su sensación de seguridad y el estrecho vínculo que tenemos. Mientras que hubiera podido presentar un caso del entramado de las tres formas de relación por parte de ambos participantes, considero que la relación intersubjetiva destacaba en las experiencias del analista y analizando durante estos momentos de abrazo.

La relación intersubjetiva requiere de una expresión más directa y extendida de la experiencia subjetiva del analista para crear una intimidad recíproca (aunque asimétrica) sujeto a sujeto.

Después de tres años de análisis, Samantha tiene el siguiente sueño que nos ofrece una extraordinaria imagen de lo que ha estado ocurriendo. El sueño se presenta en tres partes, tal y como sigue:

I. Una aldea - este se extiende arriba (y abajo) en una ladera. No se trata de una ladera empinada, sino que es gradual y elegante; es femenina. Es invierno. Contemplo la aldea como si se tratase de una maqueta de trenes. Veo los tejados, parecen viejos libros de piel posados en cada casa. Hay vías del tren que la atraviesan, dándole una unidad y conectándola, haciendo que sea un todo. Hay bosques de pinos verdes, calles principales, céntricas plazas, caminos rurales escondidos bajo la nieve. Está en calma, en paz, es hermosa. Sé que yo soy la aldea y también lo que la observa desde arriba. Es el paisaje de mí misma.

II. Siento miedo. Estoy repleta del mismo tipo de terror que me llevó al hospital. Es enorme, inmanejable, abrumador. Lo siento en todas partes, lo siento en mi piel, y dentro de mí. Estoy paralizada por el miedo. Es un miedo viejo, familiar. La aldea cae en un estado de animación suspendida. Está congelada y en calma; no hay movimiento. Mi yo que se 
encuentra en la aldea deja de sentir. Tengo ese sentimiento familiar de miedo seguido de ausencia de sentimiento.

III. El tiempo ha pasado como en la narración de la historia de Rip Van Winkle. Tengo esa sensación de que han pasado veinte años (pero sé que son más). La aldea ha permanecido en su estado de animación suspendida. He vivido sin sentimientos durante ese tiempo. Hay un deshielo; la aldea vuelve a tener vida. Las casas rurales están en el mismo lugar pero parece como si hubieran sido movidas a nuevos lugares. La conexión de los carriles del tren con las aldeas y casas rurales parece la misma al verlo desde arriba, pero mi yo que está dentro del paisaje parece diferente. Me siento desorientada, pero no asustada. Agradezco que la helada haya acabado. Hay carámbanos deshelándose en los tejados de las casas; la luz desaparece por un lugar diferente. Al final del sueño sólo estoy en el paisaje, ya no estoy por encima. Estoy tratando de encontrarme dentro de un terreno desconocido. El deshielo ha causado aparezcan bajo la nieve pedazos de tierra. El paisaje ya no es puro tal y cómo era al principio del sueño (cuando era un modelo... una hija modelo) pero siento que pertenezco a ese lugar; es mucho más real y lleno de vida.

Entendimos que el sueño representaba la historia dramática de la transformación psicológica en curso. El sueño de Rip Van Winkle durante veinte años había empezado cuando Samantha tenía 19, el comienzo de su adultez, tal y como dijo, y cuando había conocido a su anterior marido, aunque según ella, llevaba dormida más tiempo. Educada como una hija modelo, era elegante y femenina, y había conseguido algo de calma a costa de tomar distancia y "frialdad" de su propia experiencia ("Sé que yo soy la aldea y también lo que la observa desde arriba.") Durante el análisis Samantha empezó a reconectar con sus sentimientos, se encontró con el miedo y, de igual modo que en el pasado, se congeló para así detenerlo. Gradualmente al tiempo que íbamos comprendiendo y ayudándola en su trabajo de encontrarse en el miedo, ella empezó a deshelarse, empezó a estar más plenamente "dentro" de la experiencia, y a sentirse más viva.

Durante los tres siguientes años, Samantha había conseguido escribir y, cada vez más, conseguía centrarse con éxito. La publicación de su libro había sido la recompensa que había recibido y le había reforzado e incentivado aún más. Durante ese tiempo había compartido conmigo sus escritos y yo siempre me sentía profundamente agradecido y reforzado con ello. Tal y como se pone de manifiesto en los sueños, ella tiene una increíble capacidad para el lenguaje y las imágenes. Ella sabe que yo escribo y me pregunta acerca de esto. En estos "momentos presentes" (Stern, y col., 1998) hemos compartido experiencias acerca de la escritura. Hay momentos de reconocimiento mutuo, de experiencias idénticas - momentos de intimidad que implican relación intersubjetiva o de sujeto a sujeto. Claramente somos una persona frente a otra con un profundo respeto mutuo, así como preocupación el uno hacía el otro. 
Cuando se acercaba a los 40, Samantha estuvo muy afectada ante la posibilidad de no tener hijos. Ella era la última esperanza para su familia. Al pensar que sus padres se sentirían decepcionados si ella no tenía hijos, con mi empujón alentador ella habló con ellos y descubrió, para su sorpresa, que ellos no apostaban mucho por tener nietos, sino por su felicidad. Surgió la que para ella era la mejor relación romántica que había tenido hasta el momento, pero el hombre tenía hijos y no quería embarcarse en ese camino de nuevo. Debido a varios contratiempos importantes en la vida de este hombre, la relación se acabó.

Últimamente, Samantha y un amigo cercano han empezado a expresarse sentimientos sexuales y amorosos. Él estaba saliendo de otra relación. Tiempo después, la relación fue progresando, incluyendo intimidad sexual. Samantha sintió que finalmente estaba integrando la sexualidad en una relación más completa con un hombre. Mientras Samantha me contaba esto, reflexioné para mí mismo cómo me había estado sintiendo más cómodo con una intimidad que incluía, por primera vez, que yo tuviera sentimientos sexuales hacia Samantha. Sospechando esto podría no ser tan aterrador para Samantha experimentar sentimientos sexuales en nuestra relación (un ejemplo en el que el contenido de las expresiones del analizando se centra en una relación exterior y tiene significados paralelos dentro de la relación analítica, Fosshage, 1994), yo le pregunté que si su nueva integración podría tener algún significado para nosotros ${ }^{7}$. Expresé esta pregunta con cierta contingencia, a propósito, para reducir el posible desencadenamiento de un sentido de imposición. Con una sonrisa, me dijo que había sentido fugaces sentimientos sexuales hacía mí. Ahora ella sentía que el terreno de juego estaba al mismo nivel. Era más de persona a persona. Me dijo abiertamente que me quería y que sabía que yo la quería a ella. Subrayé que era amor mutuo lo que había entre los dos, ofreciéndole la visión de que, quizás, pudiera haber sentimientos sexuales como parte de estos sentimientos de amor entre ambos que simplemente podrían ser disfrutados como afirmadores el uno del otro ${ }^{8}$.

Hace poco, Samantha ha decidido coger un puesto de jornada completa, y mejor pagado, dentro del mundo del arte, encabezando su propio departamento. Ha construido una buena reputación y lo negoció de manera admirable. Por primera vez en su vida, es más consciente económicamente y desea obtener cosas para sí misma.

Antes de terminar quiero presentar de una manera resumida detalles del intercambio en una sesión reciente que tuvo lugar la mañana previa a su primer día de trabajo. El contexto de nuestro trabajo juntos durante un tiempo considerable debe tenerse en cuenta, ya que tratamos bastante rápido de aquellos asuntos que aparecen en las sesiones y que son muy familiares y en este momento desencadenados por su nuevo trabajo y con la jerga que hemos desarrollado mutuamente. Durante esta sesión Samantha enfrentándose claramente a una 
batalla temática entre ser ella misma y ser controlada por los de su entorno y por la estructura de la empresa. Empezó la sesión diciendo, "este es el primer trabajo de jornada completa que tengo desde 1991 y estoy preocupada". Yo pregunto, “¿Qué te preocupa?”. Ella responde, "Miedo a sentirme atrapada". Yo pregunto, “¿de qué manera?". Ella describe que debe comer cada dos horas (un uso prolongado de antibióticos ha desregulado por completo su organismo) y no quiere desvelarlo, ya que eso le deja en una posición de debilidad como jefa de un departamento en el que está con gente que no conoce.

Hablamos sobre algunas alternativas prácticas y acabó aún más desesperada diciendo que no quería estar ahí, que quería irse a casa. Continué explorando, "¿Hay alguna otra razón?". Ella respondió, "Es aburrido, peligroso, no sé qué estoy haciendo." Relacionó esto a sus sentimientos de sentirse atrapada en el colegio, aburrida y cohibida. Con los trabajos como freelancer, había podido estar dentro seis meses y luego "irse fuera de ahí". Con un cierto tono de súplica de no querer ser forzada a hacerlo, volvió a decir "Desinterés, claustrofobia, complejidad en las relaciones." Reflexioné yo, "Si, en una posición freelance puede trabajar seis meses y después irte de allí y estar bien." Ella dijo, "Sí, y puedo seguir haciéndolo. ¿Por qué tendría que hacer frente a compromisos impuestos? Mi compromiso contigo sale de mi deseo, de mi necesidad; yo te quiero $y$, si tenemos problemas, los resolvemos." Yo respondí, "Esto se trata de un nuevo modelo, una nueva forma de hacer las cosas, a diferencia de como parecía ser normalmente en casa". Respondió, "En casa sentía que se me llevaba a ser alguien que yo no era, no soy enteramente yo misma, tenía que ser perfecta en casa". Yo insinué, "Quizás no tengas que ser tan perfecta en el trabajo; quizás podrías tomarte un tiempo para asimilar y familiarizarte con ello." Ella entendió el mensaje, "sólo necesito un cuaderno y un lápiz hasta que averigüé lo que estoy haciendo." Ella describió varias interacciones en las que había sido honesta y "no perfecta" y entonces dijo, "Tengo ganas de matar a mi padre. El perfeccionismo viene de él. [Y con un suave tono de impotencia] Me decepciona mucho que sea tan profundo" Respondí, "Si, así es como es. Esto es lo que ocurre cuando esas redes neurales se activan [algo de lo que habíamos hablado en detalle]". Volvimos a discutir acerca de cómo uno tenía que recuperar la perspectiva y salir de un sentimiento, en su caso el sentimiento de las expectativas perfeccionistas. Ella recordó cuando al ser una niña se escapaba por su ventana y subía al tejado, para estar sola y fumar, y recobrar su serenidad. Respondí explicando y tratando de abrir esta nueva vía, "Sí, allí no podrías resolverlo dentro de las relaciones; ahora pude que si puedas; quizás puedas ser, y después puedes ser en casa allá a donde vayas." Respondió con afecto, "Eso sería maravilloso. Lo hicimos - gracias, puedo respirar de nuevo. Te quiero". Yo respondí, "Es mutuo." El asunto del perfeccionismo, el ser una niña modelo, había sido activado y rápidamente fuimos capaces de ayudarle a recobrar su nueva perspectiva y liberarse de lo anterior. Con mis 
respuestas, le ofrecía una visión de "ser" que ella ahora reconocía y con la que se relacionaba. La confirmación de nuestro éxito apareció en una sesión grupal, cuatro días más tarde, en la que ella transmitía lo ocurrido y lo feliz que se sentía desde nuestra última sesión.

Samantha y yo hemos viajado juntos a través de un largo y extraordinario camino. Durante una gran parte del análisis nuestra intimidad estaba basada en la transferencia de un objeto del self idealizado en la que yo era vivido como alguien estable, una ayuda protectora y tranquila que le daba un mapa de comprensiones acerca de su amplia gama de emociones, recuerdo y experiencias. Dicha amplia gama implicaba muy a menudo recuerdos traumáticos y disociados, y sus sentimientos. Fue una intimidad de cuidado y afecto la que surgió, para ella, de la relación con el objeto del self. Yo me preocupaba por sus necesidades, como un padre protector, el tipo de relación que he llamado "de cuidado" o preocupación por el otro.

A medida que ella consolidaba un sentido del self cohesionado y más positivo y se convertía cada vez más en su propia persona, Samantha deseó una relación más profunda en la que apareciera más mi subjetividad, ésta ya no le aterraba - una relación de sujeto a sujeto o intersubjetiva. En estos momentos nuestra intimidad se basaba en lo que ella expresó como "un terreno de juego al mismo nivel". Se trataba de una persona frente a otra, con un mayor intercambio de nuestras experiencias subjetivas con el otro. El amor y el afecto podían ser experimentados y expresados por ambos, tanto verbal como con contacto físico. Los abrazos y apretones de manos, iniciados por Samantha, eran potentes expresiones de afecto, cada una de ellas con un significado distinto, servían de reguladores de la cercanía entre nosotros. Estas expresiones verbales y de contacto físico surgen del profundo sentido de seguridad y la auto-confianza, que con mucho esfuerzo, sustituye las transgresiones de su traumática infancia y su anterior análisis.

En otras ocasiones, ella "cuidaría" de mí y mis necesidades de objeto del self pasarían a primer plano. Por ejemplo, ella expresaba su preocupación y se interesaba por mí sí me veía preocupado o cansado. Me sentía cuidado y fortalecido mutuamente por su preocupación, y ella, yo pienso, se fortalecía por su preocupación también.

Estos cambios en las necesidades y en las formas de relación pueden aparecer vertiginosos en nuestras relaciones de igual manera que ocurre en la última parte de la sesión que he comentado y es nuestro desafío sentirnos cómodos con cada una de ellas. Desde mi punto de vista, cada forma de relación nos puede aportar una experiencia íntima, cada una de ellas con una tonalidad específica. 


\section{Anexo}

\section{Viñeta Clínica (Amanda) ${ }^{9}$}

Expongo la siguiente viñeta clínica para ilustrar el rápido uso oscilante del analista con las 3 perspectivas de escucha que vengo comentando en este trabajo [En referencia a los modelos de Transferencia expuestos en mi conferencia].

Hace varios años comencé el tratamiento psicoanalítico con una mujer de unos 30 años que llamaré Amanda ${ }^{10}$. Se trataba de una mujer muy sensible y reactiva, con un sentido del humor bastante lábil y con tendencia a manifestar estados frágiles del Self. Podía sentirse vulnerable con facilidad, y experimentaba la luz natural que entraba en mi despacho tan luminosa que le resultaba tremendamente molesta, por lo que bajo su petición diariamente yo ajustaba las persianas.

Tanto el padre como la madre de Amanda habían estado considerablemente ausentes, con su madre sintiéndose a menudo agobiada. Amanda había tenido durante mucho tiempo una relación incestuosa con un hermano mayor tremendamente sádico. Cuando ella lloraba hacia su madre pidiendo ser protegida, ella solía empujar a Amanda diciéndole: "¡déjame en paz, me estás matando!". Amanda sentía que su anterior analista le había salvado la vida; él había sido realmente la primera persona que le había cuidado. Desafortunadamente él se había mudado a otra ciudad, esto había supuesto la interrupción de su largo tratamiento y el que ella tuviera que buscar otro analista.

Durante una sesión con Amanda cerca del final del primer mes de tratamiento, momento en el que quiero centrar mi comentario, comencé a sentir que en el despacho hacía demasiado calor. En silencio, me levanté y fui hacia la ventana para buscar algo de ventilación. En la siguiente sesión, la paciente comentó que le había enfadado mucho que yo me hubiera levantado en mitad de la sesión y, mientras que ella hablaba, yo me había quedado mirando por la ventana. ${ }^{11}$

Sintiéndome desconcertado por lo que para mí (opinión desde la propia perspectiva del analista) era un punto de vista idiosincrático y dañino, y sabiendo de nuestra capacidad para compartir sentido del humor que además, muy a menudo, le había ayudado a ella a volver a tomar un punto de vista de reflexión, le dije con un tono divertido y algo burlón "Señal de un buen analista: levantarse en mitad de una sesión y quedarse mirando a través de la ventana". 12 
Sin embargo, en ese instante eso fue una equivocación, ya que según la visión de la situación que tuvo Amanda era demasiado doloroso para ella seguir mi broma. Ella se había sentido invalidada, puede que incluso ridiculizada.

Recobrando mi posición empática ${ }^{13}$, le pregunté acerca de lo que había experimentado al dirigirme yo a la ventana. Amanda sintió que yo no tenía interés ninguno en lo que ella estaba diciendo. Mostrando mi preocupación, reflexioné que sus sentimientos - acerca de que yo me había ido a mirar por la ventana mientras ella hablaba y, por lo tanto, no me interesaba lo que ella comentaba - era comprensible que fuera muy dolorosos para ella (lo que mis colegas y yo hemos llamado vestir las atribuciones de la transferencia; ver Lichtenberg, Lachmannn y Fosshage, 1992).

Amanda pareció sentirse mejor una vez que yo escuché, comprendí y validé su experiencia (usando la perspectiva empática). Aun así, ella seguía sobrepasada por la ofensa y su particular asociación de lo que había ocurrido - esto era que yo había ido a mirar por la ventada mientras ella me contaba algo importante. Desde mi punto de vista, mi paciente necesitaba ser consciente y reflexionar acerca de su particular patrón para asociar situaciones, junto con los antecedentes históricos de este, para así poder recuperar plenamente el equilibrio de su self $y$, gradualmente, ser capaz de mantener una perspectiva reflexiva si este patrón aparecía en el futuro.

Con este fin, hacia el final de la sesión le pregunté a Amanda si quería saber qué me había llevado a dirigirme hacia la ventana (perspectiva del propio analista). Pensé que posiblemente nos podría ser útil la discrepancia de experiencias para así dar luz a su visión de un otro ensimismado, nada interesado y con actitud de rechazo, y le podría dar a ella una perspectiva alternativa. En cambio, negó querer saberlo.

Dos días después, en nuestra siguiente sesión, Amanda me repitió que no quería saber cuál era mi punto de vista acerca del incidente, y me dijo conmovida, "Jim, hazme un favor cuando yo entre en el despacho, revisa antes tu subjetividad en la puerta." ${ }^{14}$

En ese momento me sobresalté al sentirme controlado y negado (perspectiva centrada en el otro) y pensé para mí mismo que, anteriormente, yo (y otros) habría experimentado a Amanda como controladora. Mientras que otros analistas - abordando la situación desde una perspectiva centrada en el otro - podrían experimentar a la paciente como sádica, especialmente teniendo en cuenta la significativa relación sadomasoquista que había ella tenido con su hermano, yo no experimente el tono de su reclamación como sádico. En lugar de esto, experimenté la seriedad de su petición, y al mismo tiempo la consideración de su propio reconocimiento de lo extremo de su declaración - hasta un punto casi cómicamente absurdo, reconocido no verbalmente considero que por ambos. Este reconocimiento cómico 
me permitió "contener" mi experiencia centrada en el otro ("revisarla en la puerta") y responder fundamentalmente desde una perspectiva empática.

Con un tono implícito de desenfado y humor, sonreí a Amanda con sinceridad y le respondí "haré todo lo posible, aunque puede resultarme difícil en algunas ocasiones." Amanda fue capaz de oír que yo había captado el significado de que su subjetividad necesitaba tener prioridad en ese momento, mientras que le hacía saber que aquello no era posible del todo (algo que creo que ella ya sabía previamente). Gracias a la distensión por su parte y al incremento de un espacio de reflexión, nos centramos entonces en su experiencia y lo pobre que era consideraba que era mi interés en ella.

En varios momentos me vino a la cabeza la duda de qué ocurría cuando Amanda se sentía abrumada por mi subjetividad (una perspectiva empática se combinaba simultáneamente con mi experiencia centrada en el otro de sentirme como otro intrusivo). Interpretaba entonces con un tono cercano, "Creo que entiendo que cuando yo hago algo de repente, como por ejemplo ir hacia la ventana, o hacer referencia a mi punto de vista subjetivo, parece como si estuviera cogiendo todo el espacio, que entonces no hay sitio para ti, para tus pensamientos $y$ deseos, siento que debes haberte sentido justo así con tu hermano." ${ }^{15}$

De este modo yo confirmaba mi propia contribución a la experiencia de la paciente, observando que esto había activado un patrón experiencial (organizador) primario y relacionando con su resonancia en antecedentes históricos. En este momento Amanda se relajó de un modo notable, admitiendo que creía que yo estaba en lo cierto. Nuestro entendimiento empático se había agudizado inmensurablemente debido a mi entendimiento inicial acerca de que ella se había sentido herida y rechazada por mí.

Poco después Amanda sonrió y dijo, "Ahora puedes decirme que es lo que pasaba para que estuvieras en la ventana." Sintiéndose vista y comprendida, podía ahora dejar espacio para mi subjetividad (la propia perspectiva del analista) sin sentir la amenaza de que yo iba a ser un peligro para ella tal y como lo había sido hermano. Su cálida y abierta entrega desencadenó en mí una perspectiva empática que, simultáneamente, previno la activación de cualquier perspectiva centrada en el otro (por ejemplo, el sentimiento de estar siendo controlado).

Una vez más, la entrega del paciente fue el factor principal en provocar la perspectiva de escucha del analista. Cuando el paciente se muestra abierto y vulnerable, tal y como ocurre en este caso, esto provoca normalmente una perspectiva empática en el analista. En este caso, expliqué a Amanda que había sentido que hacía demasiado calor, asumiendo que también lo hacía para ella - ya que ella tendía a ser más calurosa que yo - y que, ya que pensé que sería más molesto interrumpirla para preguntarle de antemano, me había acercado 
sigilosamente a la ventana para abrirla un poco buscando algo de ventilación. ${ }^{16}$ Ella sonrió y se sintió tranquila al comprender la situación de un modo menos doloroso y sin sentirse rechazada. Aireando las discrepancias de nuestras experiencias conseguimos iluminar la particular perspectiva organizadora de la paciente, al mismo tiempo que nos sirvió de base para poder establecer una perspectiva alternativa.

Varios meses después, de repente Amanda recordó que su madre muy a menudo solía quedarse mirando a través de la ventana, ignorando todo lo que ocurría a su alrededor. ${ }^{17}$ Este recuerdo nos aportó una importantísima pieza adicional de su historia que cerraba así el bucle, por así decir, y nos permitía entender las particularidades de experiencias organizadas que habían sido recreadas en la relación terapéutica.

\section{REFERENCIAS}

Aron, L. (1996). A Meeting of Minds. Hillsdale, NJ: The Analytic Press.

Benjamin, J. (1988). The Bonds of Love: Psychoanalysis, Feminism, and the Problem of Domination. New York: Pantheon Books.

Benjamin, J. (1995). Like Subjects, Love Objects. New Haven: Yale University Press.

Davies, J. (1998). Between thee disclosure and foreclosure of erotic Transferencecountertransference: Can psychoanalysis find a place for adult sexuality? Psychoanalytic Dialogues, 8(6): 747-766.

Fosshage, J. (1983). The psychological function of dreams: a revised psychoanalytic perspective. Psychoanalysis and Contemporary Thought, 6, 4:641-669.

Fosshage, J. (1994). Toward reconceptualizing transference: theoretical and clinical considerations. International Journal of Psycho-Analysis, 75,_2: 265-280.

Fosshage, J. (1997a). Listening/experiencing perspectives and the quest for a facilitating responsiveness. In Conversations in Self Psychology: Progress in Self Psychology, Vol. 13, ed. A. Goldberg. Hillsdale, NJ: Analytic Press, pp. 33-56.

Fosshage, J., (1997b). The organizing functions of dreams. Contemporary Psychoanalysis, Vol. 33, No. 3, 429-458.

Fosshage, J. (2000). The meanings of touch in psychoanalysis: A time for reassessment. Psychoanalytic Inquiry, 20, 1: 21-43.

Kohut, H. (1971). The Analysis of the Self. New York: International Universities Press.

Kohut, H. (1984). How Does Analysis Cure? Hillsdale, NJ: The Analytic Press.

Lichtenberg, J., Lachmann, F. \& Fosshage, J. (1992). Self and Motivational Systems. Hillsdale, NJ: Analytic Press. 
Ruderman, E., Shane, E. and Shane, M., eds (2000). On Touch in the Psychoanalytic Situation. Psychoanalytic Inquiry, 20, 1.

Shane, M. \& Shane, E. (1996). Self psychology in search of the optimal: a consideration of optimal responsiveness, optimal provision, optimal gratification, and optimal restraint in the clinical situation. In Basic Ideas Reconsidered: Progress in Self Psychology, Vol. 12, ed. A. Goldberg. Hillsdale, NJ: Analytic Press, pp. 17-36.

Slochower, J. (1996). Holding and Psychoanalysis: A Relational Perspective. Hillsdale, NJ: The Analytic Press.

Stern, D. (1985). The Interpersonal World of the Infant, New York: Basic Books.

Stern, D., Sander, L., Nahum, J., Harrison, A., Lyons-Ruth, K., Morgan, A., Bruschweiler-Stern, N., \& Tronick, E. (1998). Non-interpretive mechanisms in psychoanalytic therapy: The "something more' than interpretation. Int. J. Psycho-Anal., 79, 903-921.

Winnicott, D.W. (1965). The Maturational Processes and the Facilitating Environment. New York: International Universities Press.

Original recibido con fecha: 2/5/2016 Revisado: 19/6/2016 Aceptado: 30/6/2016

NOTAS Y COMENTARIOS:

\begin{abstract}
${ }^{1}$ Stern y Benjamin ofrecen diferentes puntos de vista respecto a la relación intersubjetiva. Para Stern, la relación intersubjetiva emerge como un paso dentro del desarrollo normal seguido de la constitución de la esencia de la vinculación que incluye las distinciones sensoriales y físicas del self y el otro. Para ella, el reconocimiento de la subjetividad de la madre surge, en parte, a partir de la supervivencia de la agresión destructiva del niño.

${ }^{2}$ La investigación sugiere que los abrazos iniciados por el paciente tienden a experimentarse como terapéuticos, en cambio aquellos que son iniciados por el analista tienen a causar desconfianza (ver Fosshage, 2000).

${ }^{3}$ Sabemos bien lo fácil que es para un analista que aparece tras un análisis previo que ha sido potencialmente $o$ claramente problemático o, como en esta ocasión, que ha violado las directrices morales el criticar y emitir nuestro juicio. Al hacer esto, el analista pasar a llevar la parte negativa de la ambivalencia del paciente que, a su vez, obligue al paciente a proteger los aspectos positivos de su experiencia con el analista anterior y, por lo tanto, negar lo negativo. Este escenario relacional, además de los significados particulares que puede tener para el paciente, imposibilita el espacio de reflexión necesario para que el paciente exprese, reconozca y asimile el gran número de experiencias que ha tenido con el anterior analista. Tradicionalmente esta situación se observa desde una perspectiva intrapsíquica como la evidencia de la negación o escisión del paciente que ignora el importante impacto del actual analista en el paciente. Irónicamente el analista en ese momento está haciendo exactamente lo que está reclamando al paciente, escindirse

4 La tabla azul suponía una potente imagen que capturaba la libertad de movimiento, deslizándose naturalmente, una vida pacífica y la belleza. No sólo es innecesaria la traducción, sino que ésta, desde mi punto de vista, hubiera fragmentado su esfuerzo por medio del pensamiento en imágenes por capturar y expresar estos potentes significados. (Fosshage, 1983, 1997)

${ }_{5}^{5}$ Desde la teoría de los sistemas dinámicos se hubiera esperado que al cambiar uno de los miembros de la familia, en este caso Samantha, el sistema familiar y los demás miembros de la familia cambiarían.

${ }^{6}$ Remito al lector a la primera publicación en 2000 de la revista Psychoanalytic Inquiry para una consideración más integral de la cuestión del contacto físico en psicoanálisis.
\end{abstract}


7 En este momento del tratamiento no me refiero tanto al Edipo como a una sexualidad de adulto a adulto, lo que recientemente Jody Davies (1998) ha llamado, sexualidad adulta post-edípica.

${ }^{8}$ Varios analistas plantearon la cuestión de si yo, como analista, tenía o no la ventaja terapéutica de expresarle mi amor a la paciente. Si el analista siente amor hacia su paciente en momentos así, no expresarlo me parece que impide la creciente mutualidad. Además, tal y como Gary Perrin me señaló convencido, cuando el analista siente amor hacia su paciente, no reconocerlo en estos momentos desconfirmaría las percepciones de la paciente acerca de las expresiones de amor implícitas del analista y, por lo tanto, debilitaría su confianza en sus propias percepciones. También, algunos analistas se han sentido incómodos con el uso de la palabra amor. La cuestión no es qué palabra utilizamos (ya que las palabras toman distintas tonalidades y significados para cada uno), sino más bien que sentimos y somos capaces de responder con la suficiente amabilidad que permite que paciente y analista sean capaces de crear un emotivo momento de mutualidad. No hacerlo, desde mi punto de vista, sería perder la oportunidad y, puede que incluso algo peor, una posible retraumatización.

9 Viñeta Clínica extraída del artículo "El Uso y el Impacto de la Subjetividad del Analista con las Perspectivas Empáticas y de Experiencia/ Escucha del Otro ". Páginas 152 a 156. Artículo publicado en 2011 en el Volumen LXXX, Número 1 de la revista The Psychoanalytic Quarterly. Traducción castellana de Andrea Iturriaga Medrano, con comentarios añadidos traducidos por N. Monserrat Gómez

${ }^{10}$ Aspectos sobre el tratamiento de esta paciente han sido presentados y comentados previamente (Fosshage, $\left.1997^{b}\right)$

${ }^{11}$ Comentario de J. Fosshage: Acordábamos en esas claves/respuestas pero la paciente las interpretó como muy disgustada de que me haya levantado y yendo hacia la ventana en medio de algo importante que ella estaba diciendo. Las claves con las que no estábamos de acuerdo fueron el que mirara por la ventana. La claves en las que si acordábamos eran que yo me había levantado hacia la ventana y la diferencia del significado de eso para cada quien.

${ }^{12}$ Comentario de J. Fosshage: Mi humor se deshizo como un globo que se va desinflando.

${ }^{13}$ Comentario de J. Fosshage: Comprendí que esto fue una ruptura y empecé a decirle que para ella debió de haber sido algo muy molesto. Minutos antes de que terminara la sesión, habíamos establecido un contacto empático, pero yo estaba consciente de que ella seguía atrapada en su percepción de que yo me había quedado mirando hacia la ventana.

${ }^{14}$ Comentario de J. Fosshage: Ella fue lo suficientemente lista de saber que es totalmente imposible pero que de alguna manera yo me pude haber controlado o haber mantenido callado. Escuché la seriedad de esto e inmediatamente pensé en Michael Balint. Él hablaba de que cuando te metes en el área de la falla básica el analista debe de mantenerse apto para jugar. Entonces yo me sentí apto para jugar y me puse de pie en mi aptitud de juego respondiéndole "haré lo mejor que pueda para dejar afuera mi subjetividad". Eso fue suficiente y siguió hablando.

${ }_{15}$ Comentario de J. Fosshage: Lo que me vino a la cabeza cuando ella estaba hablando fue decirle "siento interrumpirte, pero creo que ahora entiendo lo que podría estar sucediendo aquí. Que cuando mi subjetividad entra a la habitación tú lo sientes como si me apoderada de todo el espacio aquí, así como lo sentías con tu hermano sádico". Ella tenía un hermano extremadamente sádico que casi le mata. Después de mi interpretación, ella se relajó al instante porque fue consciente al saber que yo entendía esto y que no le haría daño.

${ }^{16}$ Comentario de J. Fosshage: Noten que ese entendimiento alternativo de los hechos es menos tóxico de lo que ella había pensado en un primer momento. Este es un buen ejemplo de cuando compartimos nuestra subjetividad sirve para ambos, tanto el paciente que necesita saber en dónde estamos, para poder crear autenticidad y permite que el paciente comprenda que hay otra realidad, otra alternativa de porqué estaba mirando hacia la ventana.

${ }^{17}$ Comentario de J. Fosshage: 3 meses después me dice: "Sabes, recuerdo que era mi madre quien solía mirar por la ventana todo el tiempo". Aqui encontramos el tema experiencial que devino en un patrón organizador. 